Lep. Rev. (1968) 39, 4, 223-228

\title{
Leprosy in Society
}

\section{The Genesis of Lepra-Angst*}

\author{
OLAF K. SKINSNES, M.D., PH.D. \\ Professor, Department of Pathology, University of Hawaii, Honolulu, Hawaii
}

The term 'Leprofilia' (Leprophilia) has been proposed $^{1}$ to designate the phenomenon of the wish to have or be thought to have, leprosy, shown especially by some wives of leprosy patients who try to prove that they have this disease primarily so that they can remain with their segregated husbands. The self-explanatory term 'Leprophobia' is commonly used to indicate fear of leprosy. In this paper, the term 'Lepra-angst' will be employed to cover the various emotions shown by individuals who, not having leprosy, believe themselves to be so afflicted, and are disturbed by the possibility.

Experience in those medical clinics in Hong Kong which are devoted exclusively to the treatment of leprosy often leaves the observer impressed with the evident diagnostic acumen of medically illiterate peasants and common people with respect to leprosy. It is uncommon, if not rare, to have patients show up at these specialty clinics if they do not have leprosy and if other medical facilities are available to them. It is therefore remarkable, when under these circumstances, occasional persons appear at the clinics who have no evidence of leprosy but who display an agitated conviction that they are so afflicted. Enough such instances were encountered to excite curiosity and investigation as to the underlying reason for this anxiety.

\section{THE DATA}

Twenty-three patients, 2 female and 21 male, displaying lepra-angst appeared in leprosy clinics over a total period of 6 months observation. In age, they ranged from 21 to 50 years.
These patients were each interviewed on one occasion only. The interview was conducted in their own language, in a relaxed, friendly atmosphere with the interview often lasting up to 2 hours. Their concepts and tales concerning leprosy were sought and in the process their reasons for believing that they had leprosy gently probed. Subsequently these beliefs were discussed with them in the light of medical knowledge of this disease and, after careful examination had revealed no evidence of leprosy, they were assured that they did not have this disease. No follow-up was possible, but, as far as is known, none of the patients returned to this specialty clinic. None of the patients revealed any disease lesions other than small furuncles or similar minor blemishes.

The interviews were conducted against a background tapestry of information provided by a prior, extensive study of follzlore and beliefs relating to leprosy ${ }^{345}$ as held by this same ethnic group

Pertinent data for each patient are summarised in Table 1 .

INTERVIEWEES' CONCEPTS OF LEPROSY

The concepts of leprosy held by these patients in general paralleled those previously noted ${ }^{2}$ in a study of the folklore and beliefs relating to leprosy in the population of South China. Among these, the following were repeatedly reiterated and are therefore listed as contributory to an understanding of the lepra-angst.

* This study was initiated under a leprosy research and development grant from American Leprosy Missions Inc. and completed in association with studies under NIH Grant AI-03627. 
TABLE 1

Patient basis for Lepra-angst

\begin{tabular}{|c|c|c|c|c|c|c|}
\hline & Patient & Age & Sex & Marital status & Occupation & Pertinent Observations \\
\hline 1. & P.T. & 39 & M & Married & Labourer & $\begin{array}{l}\text { One year previously called on a prostitute and as a } \\
\text { result developed a feeling of 'insects crawling under the } \\
\text { skin'. Symptoms continued despite treatment, so } \\
\text { became convinced he had leprosy. }\end{array}$ \\
\hline 3. & C.S. & 28 & M & Married & Broker & $\begin{array}{l}\text { Had intercourse } 3 \text { months previously with prostitute } \\
\text { and } 3 \text { weeks later noted a skin eruption. Physician } \\
\text { diagnosed syphilis, treated same and pronounced } \\
\text { patient cured. Patient believed leprosy was contracted } \\
\text { predominantly by prostitute contact, that his health } \\
\text { was not fully normal, and that he probably harl leprosy. }\end{array}$ \\
\hline 4. & L.T.M. & 25 & M & Married & Meat dealer & $\begin{array}{l}\text { Relations with a prostitute } 5 \text { months previously and } \\
\text { believed that the usual way to contact leprosy was } \\
\text { through such contact. }\end{array}$ \\
\hline 5. & Y.C. & 24 & M & Single & Labourer & $\begin{array}{l}\text { Two years previously developed penile lesions after } \\
\text { relations with some prostitutes. Self-treated with } \\
\text { penicillin ointment. One year later developed a series of } \\
\text { pustules and presently was under treatment with } \\
\text { sulfathiazole. Believe leprosy contracted through coitus } \\
\text { with prostitutes having leprosy. }\end{array}$ \\
\hline 6. & L.M. & 26 & M & Single & Tailor & $\begin{array}{l}\text { Three years previously contracted venereal disease after } \\
\text { intercourse with some prostitutes; treated in Social } \\
\text { Hygiene Clinics. Five months previously again visited a } \\
\text { prostitute and noted inguinal lymphadenopathy. } \\
\text { Treated but believed he still was ill and that he had } \\
\text { leprosy. Believed leprosy transmitted mainly by inter- } \\
\text { course with 'bad girls'. }\end{array}$ \\
\hline 8. & C.C.C. & 40 & M & Married & Private tutor & $\begin{array}{l}\text { Would not admit extra-marital coitus. Declared strong } \\
\text { sexual interest in wife but noted that for } 4 \text { months he } \\
\text { had a fear of ejaculating during relations with her. } \\
\text { Highly agitated and fearful. Believed leprosy was } \\
\text { transmitted by sexual intercourse. Recognised a general } \\
\text { belief that people with leprosy were guilty of moral } \\
\text { misconduct. }\end{array}$ \\
\hline 9. & C.M.Y. & 50 & M & Married & Labourer & $\begin{array}{l}\text { Spent a night with a prostitute about one month } \\
\text { previously. Subsequently believed that there was slight } \\
\text { swelling of ears and face and that he had contracted } \\
\text { leprosy from this incident. }\end{array}$ \\
\hline 10. & W.C.Y. & 26 & M & Married & Merchant & $\begin{array}{l}\text { About } 6 \text { months previously the patient had related with } \\
\text { some prostitutes and subsequently noted itching of the } \\
\text { face and some dizziness. Believing that those who had } \\
\text { bed contact with 'bad girls' were most likely to contract } \\
\text { leprosy, he had this fear. }\end{array}$ \\
\hline
\end{tabular}




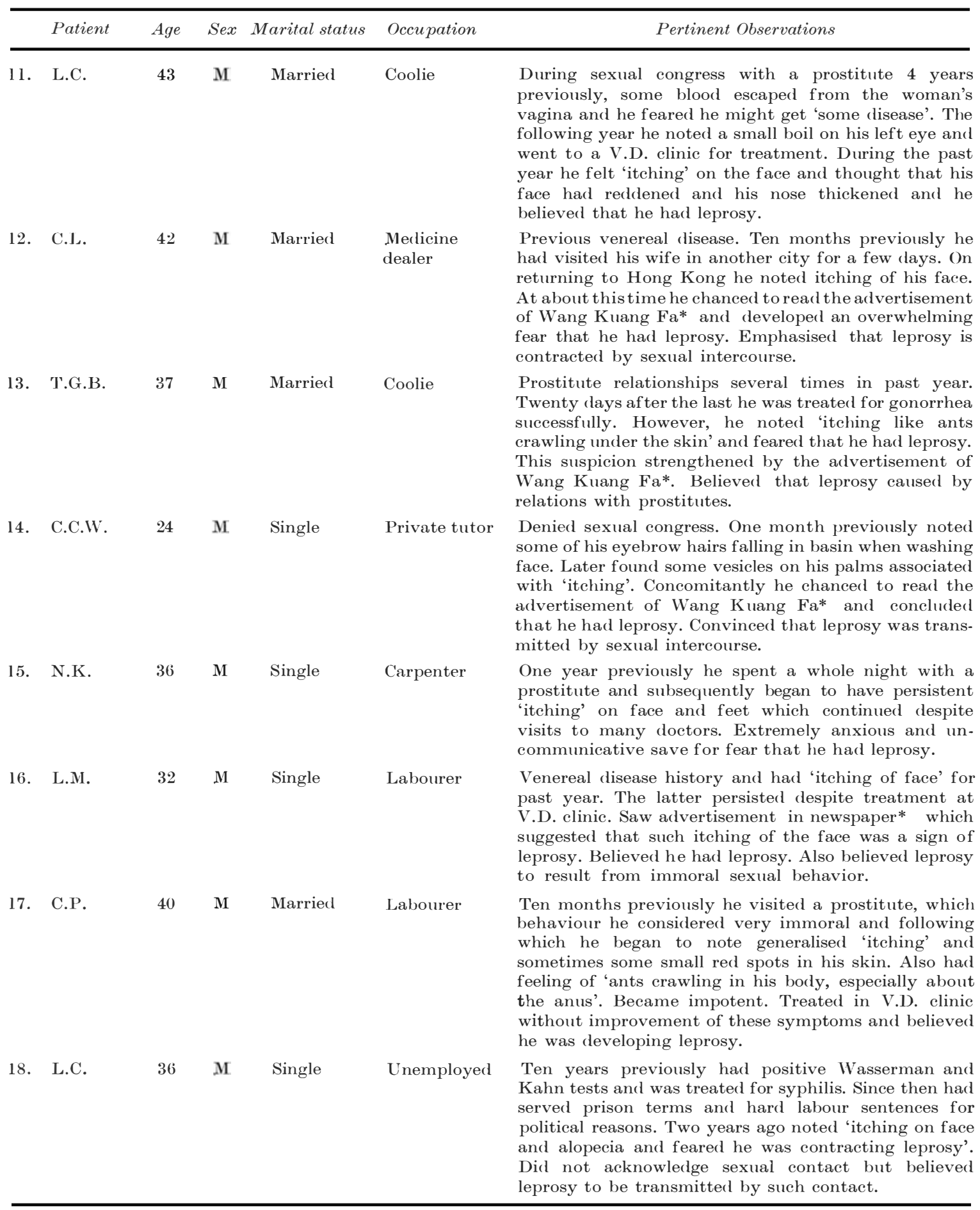

* See Fig. 1 for reproduction and translation of advertisement. 


\section{Patient Aye Seiv Marital status Occupation}

19. L.Y.S. 38 M Single

20. T.Y.S. 28 M Married

21. C.K. 27 M Married Coolie

2.2. Y.O. $37 \quad$ F $\quad$ Married Labourer

23. T.Y.P. 21 F single Student

1. The major means of contracting leprosy for males is through sexual relations with prostitutes or through abnormal human sexual relationships.

2. Leprosy is also a congenitally transmissible disease. Some patients indicated a belief that leprosy so transmitted would not reveal itself until recipient reached adulthood, married and had sexual intercourse. It would then become manifest.

3. Leprosy is incurable and there are no gods that will grant its cure.

4. If a person having leprosy can have sexual relations with a healthy individual he will, by transmitting a portion of his disease, reduce his own infection. Amelioration only, and not cure, can be thus achieved. The practice is attributed to leprous persons of either sex and is termed 'selling leprosy'.

5. Leprosy can be caused to be concentrated in less visible portions of the body by
Pertinent Observations

Three years previously the patient visited a prostitute several times and developed gonorrhea for which he was treated. Stated: 'Because I made several coitus with bad girls, I am afraid of getting such terrific disease (leprosy)'.

Patient hed his second relation with a prostitute 4 months previously and contracted syphilis. Though treated for this, he soon began to itch in his ears and then generally, with a sensation as of insects or ants crawling within his skin. As a result he developed a very nervous state, believing that he had contracted leprosy

Patient had veneral disease 8 years previously and subsequently he began to think that his eyebrows seemed to fall out easily on washing. He thought this due to syphilis but when he lately developed 'itching' inside his body he concluded that he also had leprosy. He believed that if syphilis was not cured quickly leprosy would result.

She had intercourse with her husband during menstruation and thought that this 'dirty sexual behaviour' might cause leprosy.

A very attractive young lady who blandly denied any sexual relationships and blamed some vague contact with leprosy 8 years previously for her present lepraangst.

various means such as eating small granules or ashes of silver or through consuming human placenta.

6. Persons contracting leprosy are generally 'bad' persons, having contracted it by immoral behaviour and being suspect of wishing to 'sell' it to others. The appearance of leprosy is therefore certain to cause loss of position and disgrace as well as ostracism.

7. Signs of lepsory are: enlargement of both ears, nodules on the face, loss of eyebrows, extremity deformity such as claw hands, facial and body 'itching' and a sensation as of insects crawling under the skin.

\section{DISCUSSION}

Ryrie $^{2}$, writing on the psychology of leprosy, noted that in 3 major categories of persons associated with leprosy-one of which was the patient group - there is a single common factor, namely, irrational fear. He stated, 'It must be made clear from the start that this irrational fear 

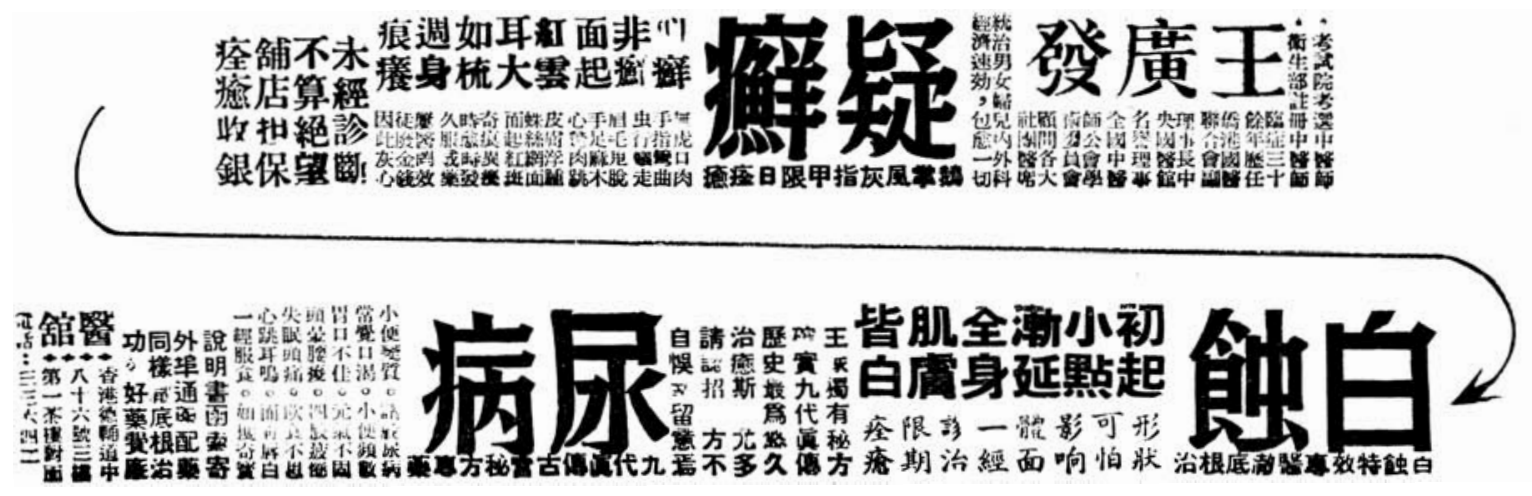

Fig. 1a

Newspaper advertisement of herbalist Wang Kuang Fa.

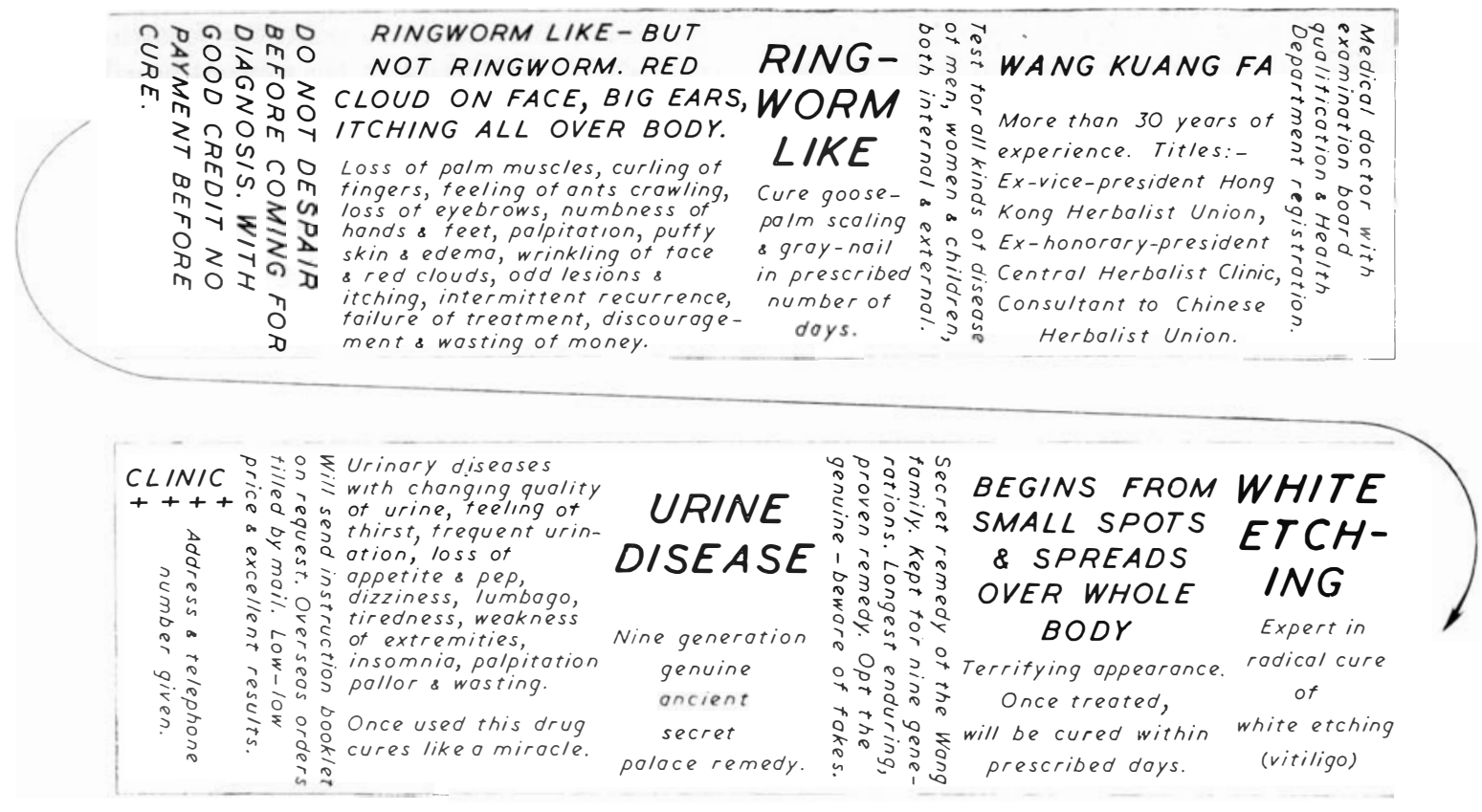

FIG. $1 b$

Translation of above advertisement. Reads from right to left.

is activated by the inherent sense of guilt which is part of the psychological inheritance of man.' He pointed to an almost universal tendency to regard leprosy as being dirty, all-infectious, cruel and venereal. Further, 'The most immediate and marked effect of the psychology of the leprosy patient is the overwhelming sense of shame and disgust, which again springs from the guilt-punishment-complex.'
The data available from this limited group of patients is so overwhelmingly similar in nearly each instance, and so compatible with previously determined social concepts of leprosy held by this ethnic group, as to suggest that the following conclusions are tenable:-

1. In the ethnic group considered, the dominant basis for lepra-angst is concern over retributive consequences of sexual 
misconduct. A strong theme of fear and guilt is found in the patients concerned and is supported by an almost compulsive need on the part of many of them to express the concept that people with leprosy are bad people who have been 'bad' sexually. The age group in which lepra-angst appeared is compatible with this conclusion as is also the preponderance of males.

2. Related to this is the fear of retributive consequences of the breaking of sexual taboos, e.g., coitus during menstruation, as demonstrated by Patient No. 22.

3. Personal, relatively casual contact with persons having leprosy is not a major factor in the development of lepra-angst.

The population of Hong Kong is only partially indigenous, there having been an increase of striking magnitude since 1948 due to refugee immigrants. Excluding this increment, a considerable portion of which came from North and Central China, the majority of the inhabitants are from South China. Though they live in Hong Kong, they maintain close connections with their home districts and reflect the customs and beliefs of these areas. When asked where their home is they will almost invariably indicate their district of origin as 'home'. All the patients, save No. 23, in this survey were from the contiguous province of Kwangtung and represented 18 districts of this province, there being 4 districts each of which was represented by 2 patients. Patient No. 2:3 was a visitor in Hong Kong from Taiwan (Formosa).

For 4 patients an apparent precipitating factor in resolving their guilt feelings into lepra-angst was the newspaper advertisement of herbalist Wang, reproduced with translation as Fig. 1. It is of interest that the advertisement does not use any specific name to identify its section referring to leprosy. It does list for this disease a greater number of signs and symptoms than for the other diseases identified. Despite the lack of name identification, none of the 4 patients had any doubt but that the advertisement referred to leprosy. It may be assumed that the list of signs and symptoms given by this experienced herbalist are those most commonly used, in this population area, to identify leprosy. The practice followed in this advertisement, which was clearly designed to attract patients by playing on their fears, suggests that in a population where leprosy is endemic it is the disease entity itself, and not the name for the disease, which carries the basic rationale for social opprobrium toward its victims. ${ }^{5}$. In all probability, any name which identifies this disease complex will call forth such opprobrium.

Much of the fear attendant on leprosy is related to misconceptions, such as those here identified as significant in the genesis of lepraangst. The greatest strides in overcoming society's lepra-opprobrium can be expected from extended publicity designed to dispel such misconceptions and to relate the known facts concerning the disease to the present possibilites of prevention, cure and rehabilitation. Individual members of society, as witness the ready response of the patients reassured in this study - referring only to their retributive association of leprosy with their guilt complex and not to any possible resolution of the guilt feeling itself - of ten respond readily to such information.

\section{SUMMARY}

Lepra-angst is identified as the guilt-fear of individuals who, not having leprosy, believe themselves to be so afflicted. Twenty-three patients, troubled by this anxiety were interviewed and the findings identify the source of their fear complex as a fear of retributive consequences of sexual peccancy. The genesis of lepra-angst in this ethnic group is correlated with prior studies of the folklore and concepts of leprosy prevalent in South China.

\section{REFERENCES}

1. MiRANDA, R. N. Leprofilia (Ou Hansenofilia): Desejo de ser Doente de Lepra. Rev. Bras. Leprol., 21, 67-68, 1953.

2. RYRIE, G. A. The Psychology of Ieprosy. Lep. Rev., 22, 13-24, 1951 .

3. Skinsnes, o. K. Leprosy in Society: I. Leprosy Has Appeared on the Face. Lep. Rev., 35, $21-35,1964$.

4. Skinsnes, o. K. Leprosy in Society: II. The Pattern of Concept and Reaction to Leprosy in Oriental Antiquity. Lep. Rev., 35, 106-122, 1964.

5. Skinsnes, o. K. Leprosy in Society: III. The Relationship of the Social to the Medical Pathology of Leprosy. Lep. Rev., 35, 175-181, 1964.

\section{Leprosy Review}

